\title{
An analysis of commercial real estate returns: an anatomy of smoothing in asset and index returns
}

Article

Accepted Version

Bond, S. A., Hwang, S. and Marcato, G. (2012) An analysis of commercial real estate returns: an anatomy of smoothing in asset and index returns. Real Estate Economics, 40 (4). pp. 637-661. ISSN 1540-6229 doi: https://doi.org/10.1111/j.15406229.2011.00327.x Available at

https://centaur.reading.ac.uk/24540/

It is advisable to refer to the publisher's version if you intend to cite from the work. See Guidance on citing.

To link to this article DOI: http://dx.doi.org/10.1111/j.1540-6229.2011.00327.x

Publisher: Wiley

All outputs in CentAUR are protected by Intellectual Property Rights law, including copyright law. Copyright and IPR is retained by the creators or other copyright holders. Terms and conditions for use of this material are defined in the End User Agreement.

www.reading.ac.uk/centaur 
Central Archive at the University of Reading

Reading's research outputs online 


\title{
An Analysis of Commercial Real Estate Returns: An Anatomy of Smoothing in Asset and Index Returns
}

\author{
Shaun A. Bond ${ }^{1}$ \\ University of Cincinnati \\ Soosung Hwang ${ }^{2}$ \\ Sungkyunkwan University \\ Gianluca Marcato ${ }^{3}$ \\ University of Reading
}

In this paper we investigate the commonly used autoregressive filter method of adjusting appraisal-based real estate returns to correct for the perceived biases induced in the appraisal process. Since the early work by Geltner (1989), many papers have been written on this topic but remarkably few have considered the relationship between smoothing at the individual property level and the amount of persistence in the aggregate appraised-based index. To investigate this issue in more detail we analyse a large sample of appraisal data at the individual-property level from Investment Property Databank (IPD). We find that commonly used unsmoothing estimates at the index level overstate the extent of smoothing that takes place at the individual property level. There is also strong support for an ARFIMA representation of appraisal returns at the index level and an ARMA model at the individual property level.

Keywords: Smoothing, Individual Properties, ARFIMA

\footnotetext{
${ }^{1}$ Department of Finance, University of Cincinnati, Lindner Hall, Cincinnati, 45242-0195. Email: shaun.bond@uc.edu.

2 Corresponding author: School of Economics, Sungkyunkwan University. 53 Myeongnun-Dong 3-Ga, Jongno-Gu, Seoul, 110-745, Korea, Email: shwang@skku.edu. The authors would like to thank seminar participants at the AREUEA annual conference, the HK-Singapore Symposium, UNSW and UTS Sydney, and in particular Yongheng Deng, Jeff Fisher, David Geltner, Tony Hall, Steve Satchell, Ko Wang and John Quigley for their helpful comments.

${ }^{3}$ School of Real Estate \& Planning, Henley Business School, University of Reading, Reading RG6 6UD, United Kingdom. Email: g.marcato@ henley.reading.ac.uk, Tel: +44 (0)118 3788178, Fax: +44 (0)118 3788172.
} 


\section{An Analysis of Commercial Real Estate Returns: An Anatomy of Smoothing in Asset and Index Returns}

In this paper we investigate the commonly used autoregressive filter method of adjusting appraisal-based real estate returns to correct for the perceived biases induced in the appraisal process. Since the early work by Geltner (1989), many papers have been written on this topic but remarkably few have considered the relationship between smoothing at the individual property level and the amount of persistence in the aggregate appraised-based index. To investigate this issue in more detail we analyse a large sample of appraisal data at the individual-property level from Investment Property Databank (IPD). We find that commonly used unsmoothing estimates at the index level overstate the extent of smoothing that takes place at the individual property level. There is also strong support for an ARFIMA representation of appraisal returns at the index level and an ARMA model at the individual property level.

Keywords: Smoothing, Individual Properties, ARFIMA 


\section{Introduction}

The treatment of appraisal-based returns has received significant attention in real estate research. Evidence from a review of real estate articles suggests that research on this topic dominates the citation list in real estate journals (Domrow and Turnbull, 2004). While an emerging strand of research has focused on transaction-based returns series (see Fisher, Gletner and Pollakowski 2007), the use of appraisal-based returns remains common in the academic literature ${ }^{4}$ and is still widely present in commercial research applications.

However, there is a widespread belief among academics that such appraisal-based returns do not accurately represent the underlying dynamics of commercial real estate returns because biases are introduced in the valuation process by appraisers. As explained in Geltner (1997) and Bowles et al. (2001), appraisers tend to review past estimates and embed that old information into their estimates, thereby dampening volatility in their price estimates. This view is based on the well known findings of Quan and Quigley (1991) and also confirmed empirically in Clayton, Geltner and Hamilton (2001). Other factors also induce econometric problems in appraisal-based indices, such as aggregation, and these issues have been discussed in Geltner (1993a) and in Bond and Hwang (2007).

The general response to this problem has been, in most cases, the application of a statistical filter to the appraisal-based returns to remove all or part of the autocorrelation in the series. The corrected or 'unsmoothed' series is then believed to reflect the dynamics in the 'true' returns process more accurately. The most common statistical filtering procedures are based on Geltner (1991, 1993b) and Fisher, Geltner and Webb (1994). More recent work has been

\footnotetext{
4 Particularly for research on countries outside of the US.
} 
conducted by Cho, Kawaguchi and Shilling (2003), Booth and Marcato (2004a, 2004b), Edelstein and Quan (2006) and Bond and Hwang (2003, 2007), and a survey of the literature has been provided by Geltner, MacGregor and Schwann (2003). However, work on smoothed returns is not confined to real estate and is also discussed in other asset classes, such as hedge funds, by Getmansky, Lo and Makarov (2004).

In contrast to the extensive volume of research on this topic and the many 'unsmoothing' procedures that have been suggested, there has been little research investigating the statistical characteristics of an aggregate performance index and its relationship to the underlying property return process. Exceptions to this include Giacotto and Clapp (1992) who provide Monte Carlo evidence on appraisal smoothing behavior, and Edelstein and Quan (2006) who compare appraisal returns with transaction information to assess the impact of smoothing.

The contribution of the current paper is to investigate the effects of smoothing at the individual and index levels for appraisal-based return series, and to identify the nature and existence of econometric problems common to such series. To do this we utilize data on individual property returns from the Investment Property Databank (IPD) for UK commercial real estate. This dataset is very similar to the NCREIF data commonly used in US research. Because of the similarity of construction methods it is believed that conclusions derived from using UK data would shed light on future studies using NCREIF data or similar appraisal-based data in other countries. ${ }^{5}$

Our methodology uses Monte Carlo simulations and bootstrapping techniques on a

\footnotetext{
${ }^{5}$ The IPD databank includes commercial real estate properties that cover approximately $50 \%$ of the overall investible market and is available with a monthly frequency. On the other hand, the NCREIF data are available at the quarterly frequency and include residential properties. However, there is little difference in the valuation process between the two datasets.
} 
sample of individual property returns to generate an aggregate index series. Knowing the individual property returns allows us to form and examine the 'true' underlying returns process for the index. This method is similar to those of Giacotto and Clapp (1992) and Edelstein and Quan (2006). The procedure clearly shows some intriguing issues that, to our knowledge, have not been well discussed in the literature.

We find several interesting results. First, the smoothing level in an appraisal-based index is not as large as in previous studies. Using a monthly frequency, we find that, at the individual property level, the smoothing parameter is as low as 0.14 when only smoothing is allowed for, while it could be up to 0.43 when both smoothing and nonsynchronous appraisal are considered. Therefore, the usual smoothing coefficient (e.g. 0.8-0.9) estimated from an appraisal-based index is not supported by the smoothing level of individual properties. Second, we find evidence of nonsynchronous appraisal. The nonsynchronous appraisal problem arises when appraisers value properties (or use information for valuation) at irregular points of time.

We propose three explanations for the large difference in the smoothing level between individual properties and an index constructed with these individual properties. One possibility is that the sample estimates are noisy because of the small number of observations for many individual properties. Using simulations we show that when the number of observations is small, e.g., 60, the estimated smoothing level of individual properties appears to be lower than the true level or even negative. A second possibility is that aggregation effects exist as suggested by Bond and Hwang (2007). When individual property returns are 'smoothed', the index constructed by cross-sectionally aggregating these individual properties shows a higher level of smoothing. Finally, we propose the possibility of a highly persistent unobserved common factor in commercial real estate returns. Then, although the smoothing level of individual properties is 
low, the aggregated process would display a high level of persistence, driven by the persistent common factor (since the idiosyncratic components of individual properties are expected to be canceled out by aggregation).

Our study has important implications for both academics and practitioners. It is likely that commonly used statistical filtering procedures could over-unsmooth the appraisal index. The level of smoothing (assuming market efficiency) commonly suggested for a monthly appraisal index (around 0.9) seems to be too large. Individual properties do not show such a high level of smoothing, nor could any cross-sectional aggregation procedure or estimation bias in small samples be completely responsible for such a high level of smoothing. Our results also suggest that when analyzing property returns, different unsmoothing methods should be used for individual property data and for the index. For example, for an investor who tries to calculate an optimal portfolio including a few real estate properties together with other assets (such as equities, bonds, etc), appraisal-based returns of the properties should be unsmoothed with an $\operatorname{ARMA}(1,1)$ model. On the other hand, institutional investors who hold a large number of real estate assets should unsmooth the overall performance of these assets with an ARFIMA model to obtain an optimal asset allocation. Otherwise, the portfolio of real estate assets would be over-unsmoothed because the smoothing level estimated with an ARMA process is in most cases higher than the one computed with an ARFIMA model.

The layout of the paper is as follows. The next section discusses the unsmoothing problem and provides a brief overview of the related literature. Section 3 describes the methodology used in this study and the sampling procedure for the individual IPD property returns. Section 4 investigates three explanations for the apparent smoothing difference between individual property and index returns. Section 5 concludes the paper. 


\section{Smoothing in Real Estate Returns}

The work on smoothing in appraisal-based real estate returns is often motivated by the apparent low historical volatility relative to mean returns on indices such as NCREIF in the US or the IPD index in the UK. This smoothness looks particularly evident when the ratio of mean return to standard deviation for real estate is compared to those of other asset classes such as equities or bonds. The academic arguments for the presence of smoothing in individual asset returns is based on the work of Quan and Quigley (1989, 1991). Empirical approaches to unsmoothing aggregate or benchmark real estate indices have previously been suggested by Blundell and Ward (1987), Geltner (1989) and Ross and Zissler (1991). Extensive summaries of the smoothing literature can be found in Geltner and Miller (2001) and Geltner, MacGregor and Schwann (2003), to which the interested reader is referred for a detailed background to the smoothing debate. It is important to point out that not all researchers agree with the widely accepted view that smoothing is present in real estate data; for example, Lai and Wang (1998) discuss a number of criticisms of the existing literature on smoothing.

We first describe asset returns at the individual and index levels as in Bond and Hwang (2007). Rather than repeating that derivation, we summarize the presentation here and refer the interested reader to the original article for a detailed explanation. Under the assumption that asset returns follow a mean plus noise process;

$$
r_{i t}=\mu_{i}+\varepsilon_{i t}
$$

where $r_{i t}$ is the log-return of asset $i$ at time $t, \underset{i t}{\stackrel{i i d}{\sim}} N\left(0, \sigma_{i}^{2}\right)$, and $\mu_{i}$ and $\sigma_{i}$ are the expected return and standard deviation of the log-returns per unit of time, respectively. Bond and 
Hwang (2007) show that the return process of asset $i$ will follow an ARMA(1,1) process,

$$
r_{c i t}-\mu_{i}=\phi_{s i}\left(r_{c i t-1}-\mu_{i}\right)+\theta_{i} \varepsilon_{c i t-1}+\varepsilon_{c i t}
$$

where $r_{\text {cit }}$ represents the asset return at time $t$ and $\varepsilon_{c i t} \stackrel{i i d}{\sim} N\left(0, \sigma_{c i}^{2}\right)$ in the presence of smoothing and nonsynchronous appraisal. Here, the AR parameter $\left(\phi_{s i}\right)$ represents the level of smoothing and the MA parameter $\left(\theta_{i}\right)$ represents the level of nonsynchronous appraisal. Further, in considering the aggregation of individual asset returns it can be shown that under the assumption that the AR parameters (smoothing levels) of individual assets follow a Beta distribution, then we have the following $\operatorname{ARFIMA}(0, d, 1)$ representation of aggregate real estate returns:

$$
(1-L)^{d}\left(r_{m t}-\mu_{m}\right)=\theta \varepsilon_{t-1}+\varepsilon_{t}
$$

where $\varepsilon_{t}$ is the market-wide, common factor. In this model, the long memory parameter $d$ of an index return series represents the average smoothing level of individual property returns whereas $\theta$ represents the average level of nonsynchronous appraisal. ${ }^{6}$ Therefore, as the overall smoothing level $\left(\phi_{s i} s\right)$ of individual properties increases in equation (2), we would expect $d$ in equation (3) (aggregate smoothing level) to approach one.

We extend Bond and Hwang (2007) by modelling the dynamics of individual asset returns $\left(\varepsilon_{i t}\right)$ with multiple factors. Let us assume that individual asset returns are modelled with multiple factors, such that

$$
\varepsilon_{i t}=\sum_{k=1}^{K} \beta_{i k} f_{k t}+\eta_{i t}
$$

where $f_{k t}$ represents the realisation of factor $k$ at time $t$, and $\eta_{i t}$ is idiosyncratic error. The

\footnotetext{
${ }^{6}$ Bond and Hwang (2007) show that when $\varepsilon_{i t}$ is iid normal and $\phi_{s i}$ follows a Beta distribution, nonsynchronous appraisal at the index level represents aggregated nonsynchronous appraisal of individual assets: i.e., $\theta=E_{c}\left(\theta_{i}\right)$, where $E_{c}($.$) represents cross-sectional expectation. However, if these assumptions are not satisfied, the relationship$ between $\theta$ and $\theta_{i}$ may not hold.
} 
factors may include type and location or other macroeconomic variables. ${ }^{7}$

By combining (4) with (1), we can obtain the following multi-factor model:

$$
r_{i t}=\mu_{i}+\sum_{k=1}^{K} \beta_{i k} f_{k t}+\eta_{i t} .
$$

When the multifactor model is cross-sectionally aggregated, the index return is

$$
\begin{aligned}
r_{m t} & =E_{c}\left(r_{i t}\right) \\
& =E_{c}\left(\mu_{i}\right)+\sum_{k=1}^{K} E_{c}\left(\beta_{i k}\right) f_{k t} \\
& =\mu_{m}+\sum_{k=1}^{K} E_{c}\left(\beta_{i k}\right) f_{k t},
\end{aligned}
$$

where $E_{c}($.$) represents cross-sectional expectation, and we have$

$$
\varepsilon_{t}=\sum_{k=1}^{K} E_{c}\left(\beta_{i k}\right) f_{k t} .
$$

In other words, when we assume that individual asset returns are modelled with multiple factors, the innovation in the market index return is also a function of these factors. For some factors, $E_{c}\left(\beta_{i k}\right)=0$ and thus these factors do not appear in the market index, whereas other factors matter at both the individual and market level. Therefore, even if the market-wide, common factor in (3) becomes a linear function of multiple factors as in (7), the $\operatorname{ARFIMA}(0, d, 1)$ model in (3) holds regardless of the factor structure.

In practice, however, the factors $\left(f_{k t} s\right)$ are not iid normal. For example, many macroeconomic variables, such as interest rates, economic growth and consumption, are highly autocorrelated. In order to model the persistence of these fundamental variables, let us assume that these factors follow a simple $\mathrm{AR}(1)$ process with autocorrelation coefficient equal to $\phi_{f}$ :

\footnotetext{
${ }^{7}$ Although multi-factor models are well defined theoretically (Ross, 1996), it is not easy to identify factors in practice. As in Chen, Hsieh and Jordan (1997) macroeconomic variables can be used as proxies for factors in real estate properties. Alternative methods to obtain factors would be using factor analysis or characteristics of properties as in Fama and French (1992).
} 
$f_{k t}=\phi_{f} f_{k t-1}+v_{k t}$. Using this simple $\mathrm{AR}(1)$ process in equation (7), we obtain an $\mathrm{AR}(1)$

process for $\varepsilon_{t}$ :

$$
\varepsilon_{t}=\phi_{f} \varepsilon_{t-1}+\xi_{t},
$$

where the AR coefficient $\left(\phi_{f}\right)$ represents the persistence level of the market-wide common factor and $\xi_{t}\left(=\sum_{k=1}^{K} E_{c}\left(\beta_{i k} v_{k t}\right)\right)$ is the innovation of the market-wide, common factor at time $t$. Then the index should be modelled by the $\operatorname{ARFIMA}(1, d, 1)$ process ${ }^{8}$

$$
(1-L)^{d}\left(1-\phi_{f} L\right)\left(r_{m t}-\mu_{m}\right)=\theta \xi_{t-1}+\xi_{t} .
$$

Moreover, if both $E_{c}\left(\beta_{i k}\right)$ and $f_{k t}$ time-vary as in Jagannathan and Wang (1996), we need a more complex nonlinear model. ${ }^{9}$

While there are strong theoretical arguments to favor the ARFIMA model of aggregate real estate returns as a basis for unsmoothing real estate returns, it is necessary to provide further evidence of the suitability of the assumptions made to develop the model and also to examine the performance of the model compared to the standard representation of real estate returns. To provide this evidence we first turn to an analysis of individual appraisal returns for the properties that comprise the benchmark monthly IPD index in the UK. Using this information to calibrate the model, we provide simulation evidence to assess the suitability of the ARFIMA model to unsmooth appraisal-based returns.

\section{Data and Smoothing Level}

\subsection{Data}

\footnotetext{
${ }^{8}$ We can very easily extend the model for $\operatorname{ARFIMA}(p, d, 1)$ when the market wide factor follows an $\operatorname{AR}(p)$ process. ${ }^{9}$ We thank the referee for bringing this point to our attention. In this study we maintain the standard assumption that factors and factor loadings are not correlated in order to focus on the main purpose of the paper.
} 
To conduct our analysis we collect information on the appraised value (capital gain) series of individual properties belonging to the IPD monthly index (appraisals are conducted on a monthly basis). As the focus of this paper is on appraisal smoothing, we concentrate on the capital gain series rather than the total returns that are calculated by aggregating capital gains and rental income. This is because rental income, which may represent a significant proportion of total return, is usually only subject to change once every five years in the $\mathrm{UK}^{10}{ }^{10}$ and thus does not reflect either the smoothing or nonsynchronous appraisal problem.

The individual properties we use in our study are the constituents of the UK IPD Monthly Index since its inception in 1987 until 2005. We analyze properties that have been included in the index for at least 60 months, in order to minimize any adverse effects (i.e. small sample problems) that arise when the AR and MA parameters are estimated. ${ }^{11}$ After allowing for this restriction, we have a total number of 3,409 properties. We then filter out 'outliers' whose characteristics are significantly different from most of the others and thus could lead to inappropriate inferences in the analysis. We remove outliers using the following procedure: average returns of individual properties should be within three standard deviations of the average return of all properties, the monthly standard deviation of a property's returns should be less than 10 percent, and the maximum and minimum monthly returns should be less than 50 percent and

\footnotetext{
10 The UK commercial real estate market works with five-yearly, upward-only rent reviews. This means that rents are only adjusted every five years. The adjustment is only upward if the market rent is above the current one. Otherwise, the rent does not change and is kept constant for another five-year period until the next rent review.

${ }^{11}$ If we consider properties with longer measurement periods in the IPD, however, we acknowledge the fact that we may also be using a sub-sample of less-frequently transacted properties, and by implication properties with lower information content, compared to the overall IPD sample. In fact, if a property in the index is sold and subsequently bought by another player adhering to the IPD databank, the IPD records the purchased property with another identifier and it is then impossible to match the previous time series with the new one, even if the two refer to the same asset included in the index. By restricting the number of observations to a minimum of 60 , we may consequently induce less volatility, thereby underestimating the degree of smoothing in the population of property returns.
} 
larger than -30 percent, respectively. By applying this procedure we remove 166 properties. Other procedures for removing outliers are related to the estimates of the $\operatorname{ARMA}(1,1)$ model. ${ }^{12}$ We face a large number of estimation errors or unusual estimates, and remove properties for which the standard errors of $\mathrm{AR}$ and MA estimates are larger than 5 or properties that have parameters that are not stationary or invertible. The additional filtering procedure removes 849 properties, the largest proportion of which is due to the nonstationarity and noninvertibility conditions imposed (621 properties). As suspected, the filtered-out properties have smaller numbers of observations than other properties in the sample (median observation is 85 months). After applying these filtering procedures we have 2,394 properties that are used for further analysis.

The statistical properties of the filtered and unfiltered individual property returns are summarized in Table 1. During the 18 years for which we have data available, the average filtered monthly return of the individual properties is 0.25 percent with an average standard deviation of 2.32 percent. The unfiltered returns of the 3,409 properties show the average monthly return of 0.29 , which is similar to that of the filtered returns. However, skewness and kurtosis of unfiltered returns are extremely large, such that Jarque-Bera statistics are more than 10 million. Our filtering procedure seems to be arbitrary, but these statistical properties indicate that AR and MA estimates of the unfiltered returns would be too noisy to be used for the analysis of smoothing.. The statistics of the relevant index returns are reported in the last three columns in the table. The average return and standard deviation of the IPD capital gains index (IPDC) are 0.29 and 0.79 percent respectively, while the IPD total return index reports an average return of

\footnotetext{
12 We use the ARMA(1,1) model rather than AR(1) model in order to select properties that can be used for both smoothing and nonsynchronous appraisal.
} 
0.88 percent. Thus, rental income consists of 68 percent of the total return. By way of comparison, returns on the FTSE Real Estate index are far more volatile and fat-tailed.

The average Sharpe ratio of individual properties is 0.12 (or in annual terms, 0.4 ), which is far less than the ratio of 0.37 for the IPDC return. The difference is mainly due to the small standard deviation of the IPD capital gain return. This clearly shows that aggregation reduces volatility since idiosyncratic errors of individual properties are cancelled out by aggregation. Therefore, the high Sharpe ratio of the index does not automatically suggest that individual properties have similar Sharpe ratios. When we include rental income, which is fixed in most cases, individual properties have an average return of 0.88 percent with average standard deviation of approximately 2.32 , giving a Sharpe ratio of 0.38 . But this is still far less than the Sharpe ratio of 1.14 obtained from the IPD total return index; the Sharpe ratio of individual properties is approximately one third of that of the index.

\subsection{Smoothing at the Individual and Index Levels}

To analyze the issue of smoothing in real estate returns, we first estimate the parameters for an $\mathrm{AR}(1)$ process for the 2,394 individual properties selected in our sample. The AR(1) process models only the impact of smoothing. The kernel density of the estimated AR parameters is shown in Figure $1 .^{13}$ The average value of AR parameters is only 0.14 with a standard deviation of 0.16 (see Panel B of Table 2). Around 16 percent of the estimated AR parameters are negative. The figure and statistics suggest weak evidence of smoothing at the individual property level; the estimated AR parameters are not significantly different from zero.

13 We use a Gaussian kernel to empirically estimate the density function. 
On the other hand, the AR estimate for the IPDC return shows a high level of persistence (i.e. the AR parameter estimate is 0.88, with standard error of 0.03; see Panel A of Table 2).

One major problem with AR processes is that the estimated AR parameter is seriously biased downwards if there is a negative MA component. In other words, as discussed in Bond and Hwang (2007), when individual properties suffer from nonsynchronous appraisal problems in addition to smoothing, the true process follows an $\operatorname{ARMA}(1,1)$ process with a negative MA coefficient. In this case the $\operatorname{AR}(1)$ process is a misspecified version of the true $\operatorname{ARMA}(1,1)$ process, and the AR estimates obtained from the AR(1) model are biased downwards. Therefore, we estimate an ARMA $(1,1)$ process for the individual property returns to obtain AR and MA parameters, each of which represents smoothing and nonsynchronous appraisal. Figures $1 \mathrm{~B}$ and $1 \mathrm{C}$ and Table 2 show some interesting patterns in the estimated AR and MA parameters. Firstly, the average value of estimated AR parameters is 0.43 , which is around three times higher than that of the $A R(1)$ process in Figure 1A. The density function is negatively skewed and the median is much higher (0.77). Thus the AR estimates from the ARMA(1,1) model suggest a much higher level of smoothing than those from the AR(1) model. Secondly, the average value of estimated MA parameters is -0.3 and the median is $-0.58 .{ }^{14}$ As explained in Bond and Hwang (2007), these negative MA parameters suggest the existence of nonsynchronous appraisal. However, when the statistics from individual properties are compared with those of the index in Panel A of Table 2, the IPDC return still shows much higher levels of persistence. The estimated AR parameter is 0.95 from the $\operatorname{ARMA}(1,1)$ model.

To conclude, this first part of our analysis suggests an intriguing set of results: both the

\footnotetext{
${ }^{14}$ We note that smoothing at the index level reflects 'average' smoothing at the individual level. Therefore, the difference between mean and median is less important in our study.
} 
$\operatorname{AR}(1)$ and $\operatorname{ARMA}(1,1)$ models show a high degree of smoothing at the index level, but smoothing decreases significantly when we consider individual properties. Our results also indicate that different models may be required to investigate smoothing between individual properties and the index. In the remainder of the paper, we intend to explain the large difference in the smoothing levels and appropriate models for individual properties and the index.

\section{Some Explanations for the Smoothing Gap}

In this section we propose three explanations for the gap between smoothing levels for individual property data and the index. The first explanation concerns whether the large number of negative AR estimates observed (appraisal overreaction) actually represents the true probability density function of the individual AR parameters. We address this concern by showing the existence of estimation biases in relation to small samples. The second explanation refers to cross-sectional aggregation increasing the persistence level in the index, as proposed by Bond and Hwang (2007). The final explanation we investigate rests on whether underlying common factors in real estate are persistent. Although the extreme persistence at the index level can be partly explained by appraisal smoothing at the individual level, it also may be due to common factors that are highly persistent, as explained in section 2 .

\subsection{Is Appraisal Overreaction Possible?}

In the sample estimates there are many negative AR estimates and positive MA estimates that are not consistent with smoothing and nonsynchronous appraisal, respectively. Appraisal overreaction suggests that appraisers overreact to information and higher valuations follow lower 
valuations, and vice versa. ${ }^{15}$ We could apply Bayesian methods to estimate the empirical density functions. With a strong prior of no appraisal overreaction, we could remove the possibility of the bimodality in the posterior distribution. However, the strong prior is not an explanation for the empirical results of many negative AR estimates and positive MA estimates.

In this subsection, we test if many negative AR estimates and positive MA estimates simply reflect estimation errors from short time series observations. Note that the AR and MA estimates are noisy and many of them are not significantly different from zero. Moreover, there may be biases in the estimates from the assets that have been included in the IPD index only for a relatively short period. In fact, we find that the correlation coefficient between AR estimates and the number of observations is positive and significant (0.183). Thus, properties that have been included in the index for short periods are likely to show lower or negative AR estimates. Figure 2 shows that the majority of properties have less than 150 months of observations and this could create small sample problems in our estimates. If we only consider properties that have stayed in the index for longer than 150 months, then Figure 3 shows that most of the AR and MA estimates are positive and negative, respectively. The median AR estimate is 0.83 and the median MA estimate is -0.67 , both of which are closer to the AR and MA estimates of the IPDC index in Table 2. This empirical result raises the possibility that small samples create a downward bias in AR estimates and an upward bias in MA estimates.

We hypothesize the possibility of estimation bias for the properties that have fewer monthly observations. In order to test the hypothesis, we perform simulations as follows. We generate 1,000 ARMA(1,1) series under the assumption that AR and MA parameters are

${ }^{15}$ Figure 1B and $1 \mathrm{C}$ may even be interpreted as bimodality or a mixture model. We tried triangular, uniform kernel, and others in addition to the Gaussian kernel. However, the large probabilities of negative AR estimates and positive MA estimates still exist. 
distributed as in Figures $3 \mathrm{~B}$ and $3 \mathrm{C}$. To explain smoothing we only allow positive AR parameters. Each ARMA $(1,1)$ series is generated to have 60 observations since our purpose is to evaluate the small sample bias. For the generated $\operatorname{ARMA}(1,1)$ series we estimate $\operatorname{AR}(1)$ and $\operatorname{ARMA}(1,1)$ models, and report kernel densities of the AR and MA estimates in Figure 4.

The AR estimates from the AR(1) process hardly show any difference between Figures $3 \mathrm{~A}$ and $4 \mathrm{~A}$. On the other hand, for the $\mathrm{ARMA}(1,1)$ process, Figures $4 \mathrm{~B}$ and $4 \mathrm{C}$ show a clear difference from Figures 3B and 3C, respectively. Even if the true AR parameters have the mass around 0.83 and are not negative (Figure 3B), the small sample estimates of AR parameters have many negative AR estimates. Similarly, the estimates of the MA parameter are upward biased.

Therefore, the distributions of AR and MA estimates in Figures 1B and 1C are affected by a large number of small observations. The number of the properties that show the large negative AR and positive MA estimates is close to zero for the properties with longer time series (150 time series observations, see Figure 3B and 3C). However, it increases significantly for the properties with short time series (60 time series observations, see Figure 4B and 4C). Both cases indicate that the bimodality of the density functions is likely to come from the estimation errors from properties with short time series observations. Taking into account the downward bias in AR estimates implies that we could have a higher level of smoothing than suggested by the original individual AR estimates. However, our choice of 60 observations provides an extreme case and thus in reality the effects of the small sample bias would be smaller than those in our simulations.

\subsection{The Effects of Cross-sectional Aggregation}

Bond and Hwang (2007) suggest that the persistence level of an index (a 
cross-sectionally aggregated process) is not necessarily equivalent to the average persistence level of individual properties. When there is smoothing and thus AR parameters are positive, an index created by aggregating the individual AR processes becomes more persistent and thus the smoothing level calculated with the index could be inflated. In order to investigate whether cross-sectional aggregation increases the persistence level of the index, we construct an index return series by aggregating the 2,394 $\mathrm{AR}(1)$ series, each of which is generated with the estimated AR parameters in Figure 1A. For the constructed index return series, we estimate $\operatorname{AR}(1)$ and $\operatorname{ARMA}(1,1)$ models. The procedure is repeated 1,000 times and the results are reported in Panel A of Table 3.

The estimated AR parameter for the pseudo index returns is 0.13 on average, which is similar to the average value of the AR parameters of the individual properties (0.14). The result indicates that if the $\mathrm{AR}(1)$ process represents the true process for the measure of smoothing, then we do not observe a high degree of smoothing (i.e. 0.88) at the index level by aggregation. The ARMA(1,1) model also does not support the high level of persistence; its average AR estimate increases by 0.1 but it is not significant. These two models of individual asset returns do not explain why we observe the high level of persistence in the IPD capital gain index.

We repeat a similar technique, except this time using an $\operatorname{ARMA}(1,1)$ as an underlying model. An index return series is created by aggregating the 2,394 ARMA(1,1) series, each of which is generated with the estimated AR and MA parameters in Figures 1B and 1C respectively. For the constructed index return series, we estimate the $\operatorname{AR}(1)$ and $\operatorname{ARMA}(1,1)$ models. The procedure is repeated 1,000 times and results are reported in Panel B of Table 3. As explained in Bond and Hwang (2007) we observe larger average values of the AR and MA parameters from the simulations than the true values in the first two columns. However, because of the large 
number of negative AR parameters we report in Figure 1B, the upward bias does not appear as severe as predicted by Bond and Hwang (2007). Interestingly, the AR parameter from the AR(1) process is still very low $(0.14)$.

The results in Table 3 suggest that some of the high smoothing level in the index can be explained by cross-sectional aggregation. Cross-sectional aggregation of individual asset returns increases smoothing levels at the aggregate level by 0.10 to 0.15 . However, it is possible that the difference between the two degrees of persistence (i.e. individual property vs index levels) is explained by both the cross-sectional aggregation and the estimation bias we analyzed in the previous section. Either explanation does not seem to resolve the difference between smoothing at the individual property and index level, but a combination of the two may well represent the answer.

\subsection{Persistent Common Factors}

Another possible explanation is that there may be unobserved common factors that are highly persistent. When individual assets are cross-sectionally aggregated, idiosyncratic errors will disappear and only common factors survive the aggregation as in equation (7). Therefore, the market-wide error term, $\varepsilon_{t}$, consists of multiple common factors. Even if appraisals fully reflect all available information (no appraisal smoothing), we would still observe a high level of persistence in the appraisal-based property returns if the common factors are highly autocorrelated; common factors may reflect changes in factors that move slowly over time.

To investigate the effects of the persistence of common factors on the persistence at the index level, we simulate the ARMA process in (2) with a common factor. Note that the innovation of individual asset returns, $\varepsilon_{i t}$, in (2) is not iid any more, but includes common 
factors that are persistent and an idiosyncratic error. For simplicity, we assume that there is only one common factor, i.e. $K=1$ in equation (7). Then we have $\varepsilon_{t}=E_{c}\left(\beta_{i k}\right) f_{k t}$ and thus $\varepsilon_{i t}=\beta_{i}^{*} \varepsilon_{t}+\eta_{i t}$ using (4). In order to analyze the effects of the persistence of the common factor on the persistence at the index level, we assume that the common factor $\left(\varepsilon_{t}\right)$ follows an $\mathrm{AR}(1)$ process as in (8).

In our simulation, we first generate the persistent common factor as

$$
\varepsilon_{t}=\phi_{f} \varepsilon_{t-1}+\xi_{t}
$$

where we set $\phi_{f}=0.1,0.3,0.5,0.7$, and 0.9 , and $\xi_{t} \sim \mathrm{N}(0,1)$. Once the persistent market-wide factor is generated, we generate the innovation $\varepsilon_{i t}$ of individual assets using

$$
\varepsilon_{i t}=\beta_{i}^{*} \varepsilon_{t}+\eta_{i t}
$$

which we obtain from equation (4) when there is only one factor. We set the distributions of $\beta_{i}^{*}$ and $\eta_{i t}$ as follows. We set $\beta_{i}^{*} \sim N\left(1, \sigma_{\beta^{*}}^{2}\right)$, and try different values for $\sigma_{\beta^{*}}$ but the results do not change in a meaningful way. ${ }^{16}$ Thus we report the results with $\sigma_{\beta^{*}}=0.3$. The common factor as a proportion of the innovation is set to 30 percent since the standard deviation of the IPD capital gain index return is around 30 percent of that of the individual properties. In other words, if we treat the IPDC return as a common factor, its standard deviation is around 30 percent of the one of individual property returns. ${ }^{17}$ Therefore, we scale $\varepsilon_{t}$ and $\eta_{i t}$ as follows: $\varepsilon_{t} \sim N\left(0,0.3^{2}\right)$ and $\eta_{i t} \sim N\left(0,0.7^{2}\right)$. Under the assumption that there are both smoothing and nonsynchronous appraisal effects, we generate 2,394 ARMA(1,1) processes, each of which has 225 observations with the estimated AR and MA parameters as in Panel B of Table 3, and then cross-sectionally

\footnotetext{
${ }^{16}$ This is because $E\left(\beta_{i}\right)=1$ regardless of $\sigma_{\beta}^{2}$. We set $E\left(\beta_{i}\right)=1$ since the factor $f_{t}$ is the market factor, similar to beta in a CAPM framework.

${ }^{17} \mathrm{We}$ also used different combinations of idiosyncratic errors to common factor, but the results do not change in a meaningful way.
} 
aggregate the 2,394 $\mathrm{AR}(1,1)$ processes to create an index.

Once the process is generated, we estimate $\operatorname{AR}(1), \operatorname{ARMA}(1,1)$, and $\operatorname{ARFIMA}(1, d, 1)$ models. We repeat the generation and estimation procedure 1,000 times and report the results in Table 4. Note that when the common factor follows an AR(1) process with the AR parameter $\phi_{f}$, the index follows an $\operatorname{ARFIMA}(1, d, 1)$ process analytically, where the AR parameter shows the persistence level of the unobserved common factor, $\phi_{f}$, the long memory parameter $d$ represents the level of smoothing in individual properties, and the MA parameter represents nonsynchronous appraisal.

The last row of Panel A of Table 2 reports that when the average smoothing level of individual properties is estimated with the index, it is 0.32 . The persistence of the common factor is 0.61 , and the nonsynchronous appraisal effect explains the negative MA of -0.29 . When the average smoothing level of individual properties is estimated with individual properties, Panel B of Table 2 shows that it is 0.43 , which is close to 0.32 . The results of our simulation in Table 4 indicate that when $\phi_{f}$ is close to 0.9 , the estimates of the $\operatorname{ARFIMA}(1, d, 1)$ model in Panel A of Table 2 can be obtained. As in Section 4.1, when only positive AR (and negative MA) parameters are allowed to generate $\operatorname{ARMA}(1,1)$ processes, the long memory parameter $d$, which represents the average level of appraisal smoothing for individual properties, would become much higher.

Therefore, an unobserved common factor could explain the difference in the smoothing level between individual properties and the index. The close comparison between the simulation and estimation results indicates that the unobserved common factor could be highly persistent, while at the same time having a low level of smoothing at the individual property level (e.g. a coefficient of $d$ of less than 0.5). 


\section{Conclusion}

This paper has investigated the suitability of widely used stochastic representations of real estate returns and in doing so we have attempted to explain some of the 'stylized facts' of real estate returns at an individual property level and an aggregate index level. This is important as many of the unsmoothing procedures used by researchers are based on assumptions about how appraisers' behavior impacts reported individual property returns, but are at the same time almost always applied to aggregate index returns. We believe that applying these unsmoothing methods at the index level severely overestimates the implied level of smoothing that actually takes place at the individual property level.

Our analysis of individual property-level returns identifies an intriguing difference in smoothing between individual property and index level returns. We observed small degrees of smoothing at the individual property level and yet a high level of persistence in aggregate index returns. This means that models of appraisal smoothing that apply AR filters to the aggregate index will overstate the extent of smoothing and may give misleading information about the nature of 'true' real estate return processes. We investigated three possible explanations for this difference.

The first explanation concerned the extent to which estimation errors (in particular, small sample biases) may have impacted the estimates of the stochastic processes at the individual property level. These biases may have underestimated the extent to which smoothing is a problem at the individual property level. We found some evidence to suggest that the downward bias in the smoothing parameter is greater for properties with fewer observations. As many properties included in the IPD Monthly index had only been constituents for less that ten years, it 
is possible that this could account for some of the discrepancy observed. Morever, our results indicate that property researchers outside the US, UK, or other countries where time series are long enough for analysis, need to minimise small sample biases. Advanced econometric tools such as bootstrapping or Bayesian methods that incorporate experts' opinion could be useful for this purpose.

The second explanation referred to the fact that the aggregation of individual property returns leads to high levels of persistence at the index level. Using the work of Bond and Hwang (2007) we considered the process of aggregation and found that, while this can account for part of the difference between smoothing at the individual property level and persistence at an index level, it may not account for all of it.

Finally, we investigated the possibility that the stochastic process underlying individual appraisal-based property returns is more complex than previously thought. While most of the literature has focused on the autoregressive component of smoothed returns, and recent consideration has been given to an ARFIMA process to capture both smoothing and nonsynchronous appraisal, there may be evidence of common factors that are highly persistent. On the statistical evidence presented here, this explanation also describes the difference between the low level of smoothing at the individual property level and the high persistence in the aggregate index. If this model is appropriate, it would have important implications for our understanding of the property market at the micro level and would further raise questions about market efficiency and the nature of the appraisal process.

In terms of advice to researchers on using unsmoothing procedures, there is strong evidence that simple AR filtering models are not appropriate. There is some evidence to support the use of the ARFIMA representations put forward by Bond and Hwang (2007). This class of 
model is the only one that goes some way toward capturing the complexity of the relationship between individual property returns and the aggregate real estate index. Between several models, the ARFIMA $(1, d, 1)$ seems best able to replicate the persistence in the aggregregate index while also being most consistent with the level of appraisal smoothing found in our analysis of individual property returns. However, further work is required to understand the nature of the process that could give rise to a common factor representation of real estate returns. 


\section{References}

Blundell, G. and C. Ward. 1987. Property Portfolio Allocation: A Multifactor Model. Land Development Studies 4: 145-156.

Bond, S.A and S. Hwang. 2003. A Measure of Fundamental Volatility in the Commercial Property Market. Real Estate Economics 31: 577-600.

and . 2007. Smoothing, Nonsynchronous Appraisal and Cross-Sectional Aggregation in Real Estate Price Indices. Real Estate Economics 35: 349-382.

Booth, P. and G. Marcato. 2004a. The measurement and modelling of commercial real estate performance. British Actuarial Journal 10: 5-61.

and . 2004b. The dependency between returns from direct real estate and returns from real estate shares. Journal of Property Investment and Finance 22: 147-161.

Bowles G., McAllister P. and Tarbert H. 2001. An assessment of the impact of valuation error on property investment performance measurement. Journal of Property Investment and Finance 19: 139-155.

Chen, S., C. Hsieh and B. D. Jordan, 1997, Real estate and the arbitrage pricing theory: Macrovariables vs. Derived Factors, Real Estate Economics 25, 505-23.

Cho, H., Kawaguchi, Y. and J. Shilling. 2003. Unsmoothing Commercial Property Returns: A Revision to Fisher-Geltner-Webb's Unsmoothing Methodology. Journal of Real Estate Finance and Economics 27: 393-405.

Clayton, J., Geltner, D. and S. Hamilton. 2001. Smoothing in Commercial Property Valuations: Evidence from Individual Appraisals. Real Estate Economics 29: 337-360.

Domrow, J. and G.K. Turnbull. 2004. Trends in Real Estate Research, 1988-2001: What's Hot and What's Not. Journal of Real Estate Finance and Economics 29: 47-70.

Edelstein, R.H. and D.C. Quan. 2006. How Does Appraisal Smoothing Bias Real Estate Returns Measurement? Journal of Real Estate Finance and Economics 32: 41-60.

Fama, E. F., and K. R. French, 1992, The Cross Section of Expected Stock Returns, Journal of Finance 47, 427-465.

Fisher, J., Geltner, D. and H. Pollakowski. 2007. A Quarterly Transactions-Based Index (TBI) of Institutional Real Estate Investment Performance and Movements in Supply and Demand. Journal of Real Estate Finance and Economics 34: 5-33.

Fisher, J., Geltner, D. and R. Webb. 1994. Value Indices of Commercial Real Estate: A 
Comparison of Index Construction Methods. Journal of Real Estate Finance and Economics 9: 137-164.

Geltner, D. 1989. Bias in Appraisal-based Returns. Journal of the American Real Estate and Urban Economics Association 17: 338-352.

. 1991. Smoothing in Appraisal-based Returns. Journal of Real Estate Finance and Economics 4: 327-345.

. 1993a. Temporal Aggregation in Real Estate Return Indices. Journal of the American Real Estate and Urban Economics Association 21: 141-166.

. 1993b. Estimating Market Values from Appraised Values without Assuming an Efficient Market. Journal of Real Estate Research 8: 325-345.

. 1997. The use of appraisals in portfolio valuation and index construction. Journal of Property Valuation and Investment 15: 423-447.

, B. D. MacGregor and G. M. Schwann. 2003. Appraisal Smoothing and Price Discovery in Real Estate Markets. Urban Studies 40: 1047-1064.

, and N.G. Miller. 2001. Commercial Real Estate Analysis and Investments, South-Western Publishing, Mason, Ohio.

Getmansky, M., Lo, A.W. and I. Makarov. 2004. An Econometric Model of Serial Correlation and Illiquidity in Hedge Funds Returns. Journal of Financial Economics 74: 529-609.

Giacotto, C. and J. Clapp. 1992. Appraisal-based Real Estate Returns under Alternative Market Regimes. Journal of the American Real Estate and Urban Economics Association 20: $1-24$.

Jagannathan, R. and Z. Wang. 1996. The Conditional CAPM and the Cross-Section of Expected Returns. Journal of Finance 51(1): 3-53.

Lai, T-Y. and K. Wang. 1998. Appraisal Smoothing: The Other Side of the Story. Real Estate Economics 26: 511-535.

Quan, D.C. and J. Quigley. 1989. Inferring an Investment Return Series for Real Estate from Observations on Sales. Journal of the American Real Estate and Urban Economics Association 17: 218-230.

and 1991. Price Formation and the Appraisal Function in Real Estate. Journal of Real Estate Finance and Economics 4: 127-146.

Ross, S. 1976. The arbitrage theory of capital asset pricing. Journal of Economic Theory 
13 (3): 341-360.

Ross, S. and R. Zisler. 1991. Risk and Return in Real Estate. Journal of Real Estate Finance and Economics 4: 175-190. 
Table 1 Statistical Properties of Individual Property Returns

\begin{tabular}{|c|c|c|c|c|c|c|c|c|c|}
\hline & \multicolumn{6}{|c|}{ Capital Gains of Individual Properties } & \multirow{2}{*}{\multicolumn{3}{|c|}{ Indices }} \\
\hline & \multicolumn{3}{|c|}{ Unfiltered Returns (3409 Properties) } & \multicolumn{3}{|c|}{ Filtered Returns (2394 Properties) } & & & \\
\hline & Mean & $\begin{array}{l}\text { Standard } \\
\text { Deviation }\end{array}$ & $\begin{array}{l}\text { Number of } \\
\text { Observations }\end{array}$ & Mean & $\begin{array}{l}\text { Standard } \\
\text { Deviation }\end{array}$ & $\begin{array}{l}\text { Number of } \\
\text { Observations }\end{array}$ & $\begin{array}{l}\text { IPD Capital } \\
\text { Gain Index }\end{array}$ & $\begin{array}{l}\text { IPD Total } \\
\text { Return } \\
\text { Index }\end{array}$ & $\begin{array}{l}\text { FTSE Real } \\
\text { Estate } \\
\text { Index }\end{array}$ \\
\hline Mean & 0.29 & 2.81 & 104.09 & 0.25 & 2.32 & 107.96 & 0.29 & 0.88 & 0.95 \\
\hline Median & 0.28 & 2.23 & 94.00 & 0.25 & 2.12 & 99.00 & 0.22 & 0.82 & 1.29 \\
\hline Maximum & 17.10 & 163.87 & 225.00 & 1.77 & 8.42 & 225.00 & 2.88 & 3.61 & 18.01 \\
\hline Minimum & -3.28 & 0.20 & 60.00 & -1.76 & 0.50 & 60.00 & -2.24 & -1.76 & -30.87 \\
\hline Std. Dev. & 0.61 & 4.39 & 37.38 & 0.37 & 0.99 & 38.58 & 0.79 & 0.77 & 5.79 \\
\hline Skewness & 10.89 & 23.75 & 1.27 & -0.24 & 1.30 & 1.15 & 0.32 & 0.25 & -0.88 \\
\hline Kurtosis & 272.29 & 737.04 & 4.39 & 4.34 & 5.55 & 3.93 & 0.75 & 1.21 & 3.69 \\
\hline Jarque-Bera & $1.0 \mathrm{E}+07$ & $7.7 \mathrm{E}+07$ & $1,184.5$ & 201.3 & $1,320.0$ & 610.6 & 9.2 & 16.0 & 156.7 \\
\hline Probability & 0.00 & 0.00 & 0.00 & 0.00 & 0.00 & 0.00 & 0.00 & 0.00 & 0.00 \\
\hline \multicolumn{7}{|l|}{$\begin{array}{c}\text { Autocorrelation } \\
\text { with Lag } 1\end{array}$} & 0.88 & 0.88 & 0.17 \\
\hline
\end{tabular}

Note: The individual properties are the constituents of the UK IPD index, which have been used to construct the IPD index from 1987 to 2005. We take properties that have ever been included in the index for at least 60 months. With this restriction we initially take a total number of 3409 properties, and report properties of capital gain returns of individual properties in the first three columns of the table. We also filter out 'outliers' whose properties are significantly different from most of the others. Outliers are removed with the following procedure. Average returns of individual properties should be within the three standard deviations of the average returns, monthly standard deviation of property returns should be less than 10 percent, and maximum and minimum monthly returns should be less than 50 percent and larger than -30 percent respectively. Using estimates of the ARMA $(1,1)$ model we also remove properties for which the standard errors of AR amd MA estimates are larger than 5 or properties that are not stationary or invertible. After applying these filtering procedures we have 2394 properties that are used for our analysis. 


\section{Table 2 Estimates of AR(1) and ARMA(1,1) Models}

\section{A. Estimates for the IPD Capital Gain Index Returns}

\begin{tabular}{|c|c|c|c|c|c|}
\hline & AR Parameter & MA Paramater & d Parameter & $\begin{array}{c}\text { AR3 } \\
\text { Parameter }\end{array}$ & AIC \\
\hline AR(1) Process & $\begin{array}{c}0.881 \\
(0.031)\end{array}$ & & & 0.872 \\
\hline ARMA(1,1) Process & 0.946 & -0.315 & & & 0.786 \\
\hline ARFIMA(1,d,1) & 0.930 & -0.427 & 0.136 & & 0.790 \\
Process & $(0.032)$ & $(0.124)$ & $(0.141)$ & & 0.788 \\
\hline ARFIMA(1,d,1) & 0.609 & -0.292 & 0.319 & 0.236 & $(0.111)$ \\
Process & $(0.179)$ & $(0.140)$ & $(0.152)$ & & \\
\hline
\end{tabular}

B. Estimates for the 2394 Individual Properties Returns

\begin{tabular}{|c|c|c|c|}
\hline \multirow{2}{*}{} & \multicolumn{3}{|c|}{ Estimated Models } \\
\cline { 2 - 4 } & AR(1) Process & \multicolumn{2}{|c|}{ ARMA(1,1) Process } \\
\cline { 2 - 4 } & AR Parameter & AR Parameter & $\begin{array}{c}\text { MA } \\
\text { Paramater }\end{array}$ \\
\hline Mean & 0.141 & 0.425 & -0.296 \\
Median & 0.130 & 0.770 & -0.580 \\
Standard Deviations & 0.156 & 0.631 & 0.601 \\
Skewness & 0.218 & -1.078 & 0.918 \\
Kurtosis & 4.161 & 2.586 & 2.325 \\
\hline
\end{tabular}

Notes: The models in panel A are estimated using 225 monthly returns of the IPD Capital Gain index from January 1987 to September 2005. In panel A we add an AR(3) component to model seasonality in the monthly IPD Capital Gain index returns, which arises on a quarterly basis. The estimates in panel B are calculated using 2,394 individual properties described in Table 1. 


\section{Table 3 Estimates of AR(1) Model and Simulated Index from AR(1) Process}

A. Estimates from Simulated Index Returns Using AR(1) Process

\begin{tabular}{|c|c|c|c|c|}
\hline \multirow{2}{*}{} & $\begin{array}{c}\text { Data generating } \\
\text { Process: AR(1) } \\
\text { Process }\end{array}$ & $\begin{array}{c}\text { AR(1) } \\
\text { Process }\end{array}$ & \multicolumn{2}{|c|}{ ARMA(1,1) Process } \\
\cline { 2 - 5 } & AR Parameter & AR Parameter & $\begin{array}{c}\text { AR } \\
\text { Parameter }\end{array}$ & $\begin{array}{c}\text { MA } \\
\text { Paramater }\end{array}$ \\
\hline $\begin{array}{c}\text { Average } \\
\text { Estimate } \\
\begin{array}{c}\text { Standard Errors } \\
\text { of Estimates }\end{array}\end{array}$ & 0.141 & 0.128 & 0.248 & -0.145 \\
\hline
\end{tabular}

B. Estimates from Simulated Index Returns Using ARMA(1,1) Process

\begin{tabular}{|c|c|c|c|c|c|}
\hline & \multirow{2}{*}{\multicolumn{2}{|c|}{$\begin{array}{c}\text { Data Generating Process: } \\
\text { ARMA }(1,1) \text { Process }\end{array}$}} & \multicolumn{3}{|c|}{ Estimated Models } \\
\hline & & & \multirow{2}{*}{$\begin{array}{c}\text { AR(1) } \\
\text { Process } \\
\text { AR } \\
\text { Parameter }\end{array}$} & \multicolumn{2}{|c|}{ ARMA(1,1) Process } \\
\hline & AR Parameter & $\begin{array}{c}\text { MA } \\
\text { Paramater }\end{array}$ & & AR Parameter & $\begin{array}{c}\text { MA } \\
\text { Paramater }\end{array}$ \\
\hline $\begin{array}{l}\text { Average } \\
\text { Estimate }\end{array}$ & 0.425 & -0.296 & 0.138 & 0.565 & -0.442 \\
\hline $\begin{array}{c}\text { Standard Errors } \\
\text { of Estimates }\end{array}$ & $(0.631)$ & $(0.601)$ & $(0.073)$ & $(0.411)$ & $(0.422)$ \\
\hline
\end{tabular}

Notes: The table summarizes the simulation results. We construct an index return series $(225$

observations) by aggregating the 2,394 AR(1) series, each of which are generated using the estimated AR parameters. Error terms are drawn randomly from the normal distributions whose standard deviations are set to estimated standard deviations of residuals. For the constructed index return series, we estimate $\operatorname{AR}(1)$ and $\operatorname{ARMA}(1,1)$ models. The procedure is repeated 1000 times. 
Table 4 Simulations for Common Factors

\begin{tabular}{|c|c|c|c|c|c|c|c|}
\hline & \multirow{3}{*}{$\begin{array}{c}\begin{array}{c}\text { Persistence of } \\
\text { Common } \\
\text { Factor }\end{array} \\
\text { AR Parameter }\end{array}$} & \multicolumn{6}{|c|}{ Estimated Models } \\
\hline & & \multirow{2}{*}{$\begin{array}{c}\text { AR(1) } \\
\text { Process } \\
\text { AR Parameter }\end{array}$} & \multicolumn{2}{|c|}{ ARMA(1,1) Process } & \multicolumn{3}{|c|}{ ARFIMA $(1, \mathrm{~d}, 1)$ Process } \\
\hline & & & $\begin{array}{c}\text { AR } \\
\text { Parameter } \\
\end{array}$ & $\begin{array}{c}\text { MA } \\
\text { Paramater } \\
\end{array}$ & $\begin{array}{c}\mathrm{d} \\
\text { Parameter } \\
\end{array}$ & $\begin{array}{c}\mathrm{AR} \\
\text { Paramater } \\
\end{array}$ & $\begin{array}{c}\text { MA } \\
\text { Paramater }\end{array}$ \\
\hline Average Estimate & \multirow[b]{2}{*}{0.100} & 0.245 & 0.522 & -0.305 & 0.123 & 0.103 & 0.002 \\
\hline $\begin{array}{c}\text { Standard Errors of } \\
\text { Estimates }\end{array}$ & & $(0.077)$ & $(0.291)$ & $(0.312)$ & $(0.243)$ & $(0.439)$ & $(0.410)$ \\
\hline Average Estimate & \multirow[b]{2}{*}{0.300} & 0.438 & 0.523 & -0.109 & 0.079 & 0.264 & 0.079 \\
\hline $\begin{array}{c}\text { Standard Errors of } \\
\text { Estimates }\end{array}$ & & $(0.060)$ & $(0.159)$ & $(0.193)$ & $(0.273)$ & $(0.411)$ & $(0.315)$ \\
\hline Average Estimate & \multirow[b]{2}{*}{0.500} & 0.642 & 0.658 & -0.032 & 0.121 & 0.488 & 0.019 \\
\hline $\begin{array}{c}\text { Standard Errors of } \\
\text { Estimates }\end{array}$ & & $(0.061)$ & $(0.100)$ & $(0.116)$ & $(0.307)$ & $(0.313)$ & $(0.270)$ \\
\hline Average Estimate & \multirow[b]{2}{*}{0.700} & 0.797 & 0.781 & 0.044 & 0.140 & 0.692 & -0.007 \\
\hline $\begin{array}{c}\text { Standard Errors of } \\
\text { Estimates }\end{array}$ & & $(0.041)$ & $(0.054)$ & $(0.075)$ & $(0.294)$ & $(0.177)$ & $(0.230)$ \\
\hline Average Estimate & \multirow[b]{2}{*}{0.900} & 0.940 & 0.928 & 0.097 & 0.288 & 0.771 & -0.028 \\
\hline $\begin{array}{c}\text { Standard Errors of } \\
\text { Estimates }\end{array}$ & & $(0.023)$ & $(0.029)$ & $(0.066)$ & $(0.279)$ & $(0.291)$ & $(0.204)$ \\
\hline
\end{tabular}

Notes: The table summarizes the simulation results. We construct an index return series (225 observations) by aggregating the 2,394 AR(1) series each of which are generated with the estimated AR parameters. Error terms are drawn randomly from the normal

distributions whose standard deviations are set to estimated standard deviations of residuals. For the constructed index return series, we estimate the $\operatorname{AR}(1), \operatorname{ARMA}(1,1)$, and $\operatorname{ARFIMA}(1, \mathrm{~d}, 1)$ models. The procedure is repeated 1000 times. As in Table 2 ARMA(1,1) processes are generated using the estimated AR and MA parameters. 
Figure 1A Kernel Density of AR Estimates of AR(1) Process

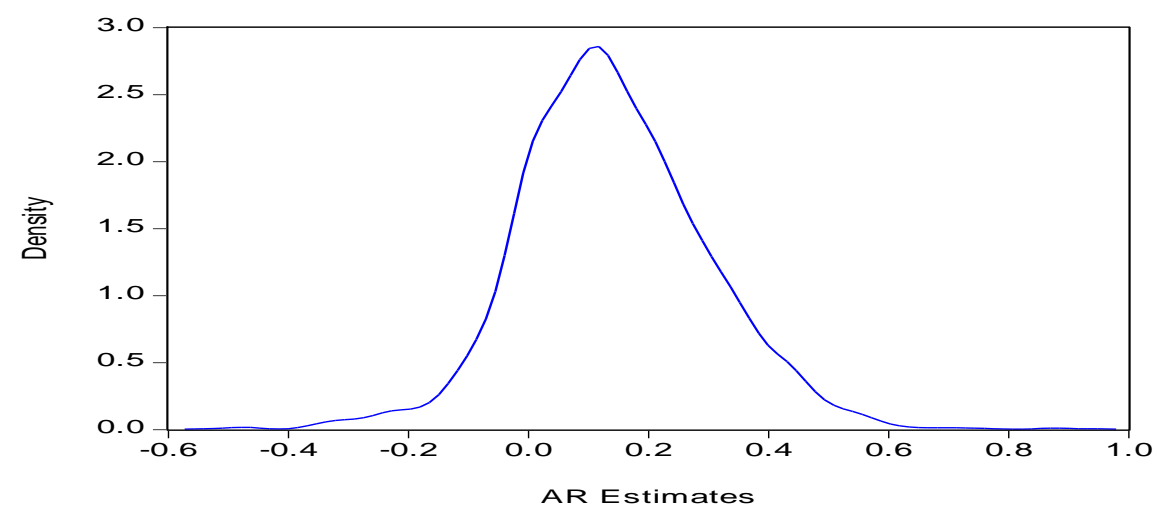

\begin{tabular}{|c|ccccc|}
\hline \multirow{2}{*}{ Statistics of AR Estimates } & Mean & Median & Std. Dev. & Skewness & Kurtosis \\
\cline { 2 - 6 } & 0.141 & 0.130 & 0.156 & 0.218 & 4.161 \\
\hline
\end{tabular}

Figure 1B Kernel Density of AR Estimates of ARMA(1,1) Process

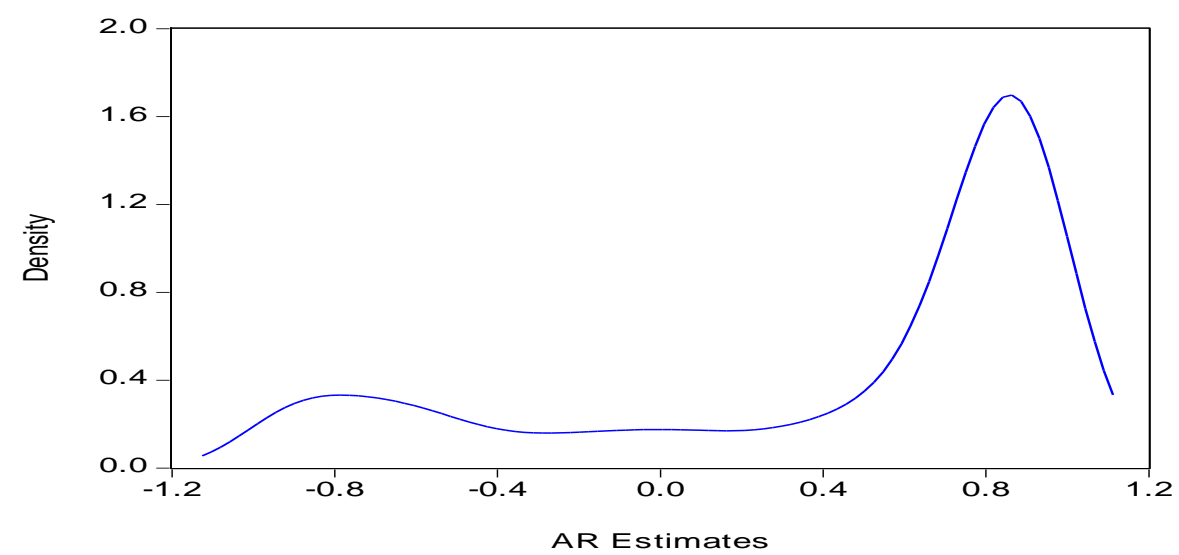

\begin{tabular}{|c|ccccc|}
\multirow{2}{*}{ Statistics of AR Estimates } & Mean & Median & Std. Dev. & Skewness & Kurtosis \\
\cline { 2 - 6 } & 0.425 & 0.770 & 0.631 & -1.078 & 2.586 \\
\hline
\end{tabular}

Figure 1C Kernel Density of MA Estimates of ARMA(1,1) Process

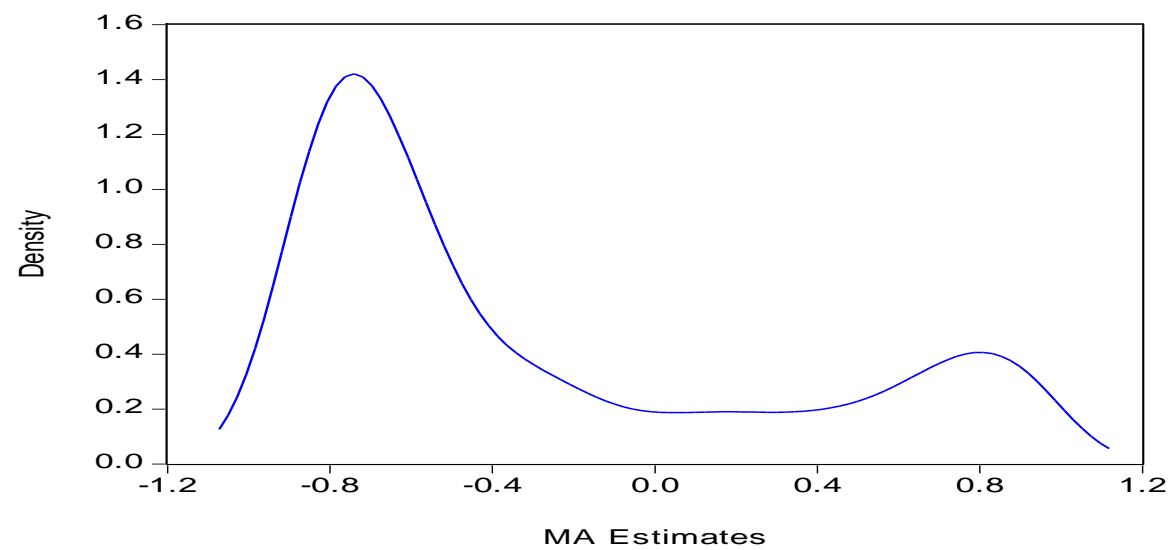

\begin{tabular}{|c|ccccc|}
\hline \multirow{2}{*}{ Statistics of AR Estimates } & Mean & Median & Std. Dev. & Skewness & Kurtosis \\
\cline { 2 - 6 } & -0.296 & -0.580 & 0.601 & 0.918 & 2.325 \\
\hline
\end{tabular}


Figure 2 Number of Observations

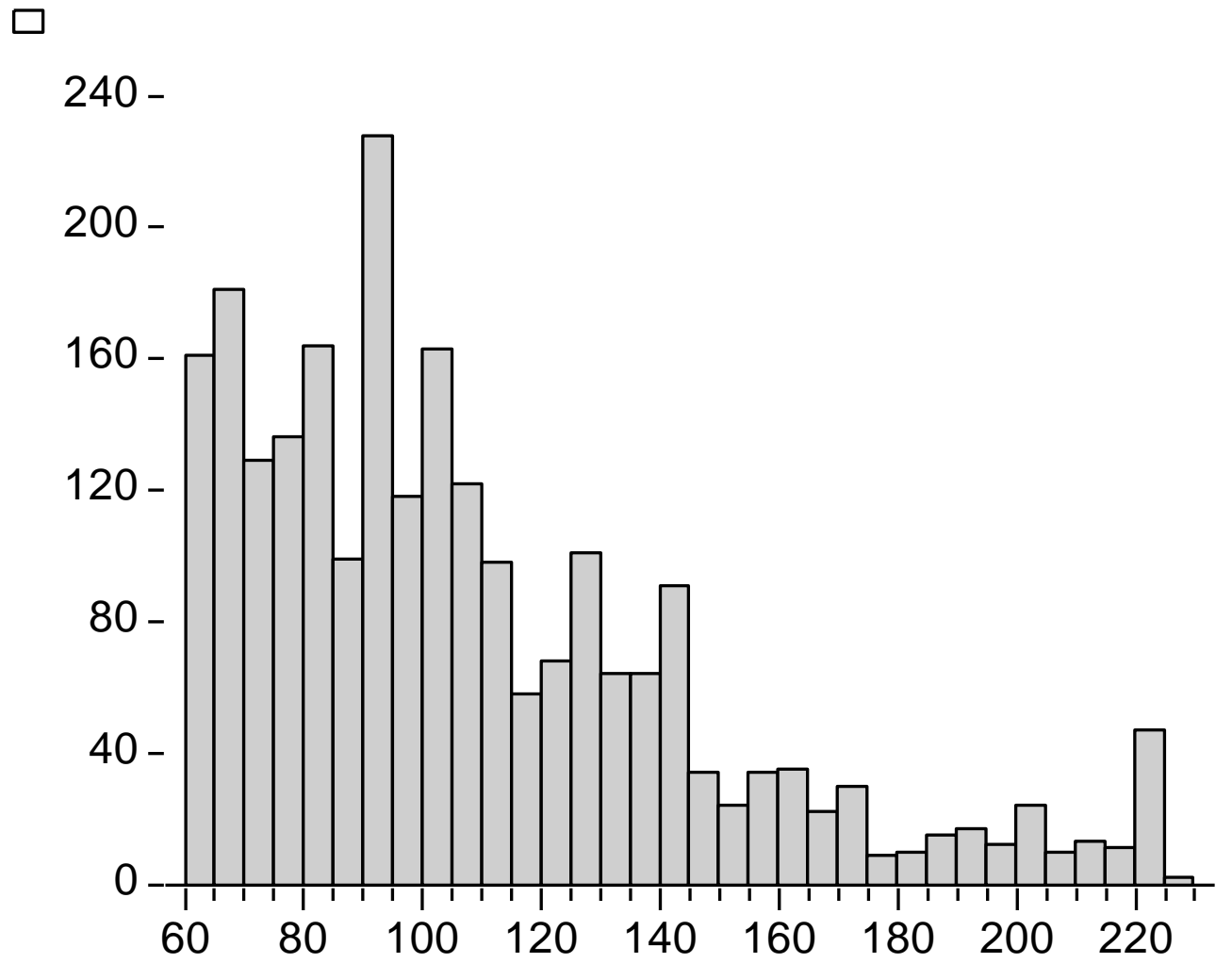

\begin{tabular}{|c|ccccc|}
\hline Statistics of AR & \multicolumn{1}{l}{ Mean } & Median & Std. Dev. & Skewness & Kurtosis \\
\cline { 2 - 6 } Estimates & 107.961 & 99.000 & 38.581 & 1.146 & 3.932 \\
\hline
\end{tabular}


Figure 3A Kernel Density of AR Estimates of AR(1) Process

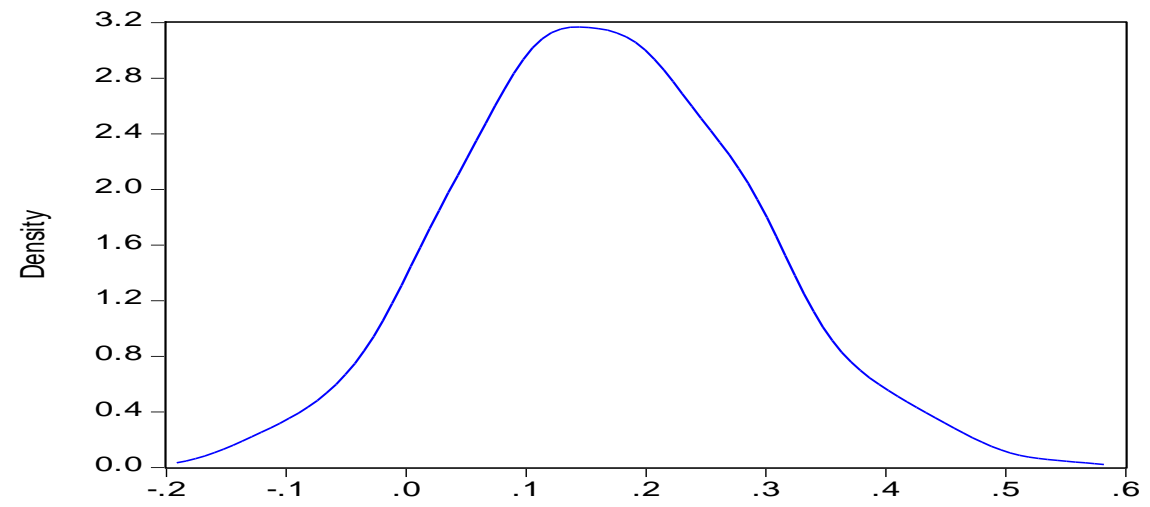

\begin{tabular}{|c|crrrr|}
\hline Statistics of AR & Mean & Median & Std. Dev. & Skewness & Kurtosis \\
\cline { 2 - 6 } Estimates & 0.166 & 0.166 & 0.121 & 0.145 & 2.956 \\
\hline
\end{tabular}

Figure 3B Kernel Densitv of AR Estimates of ARMA(1.1) Process

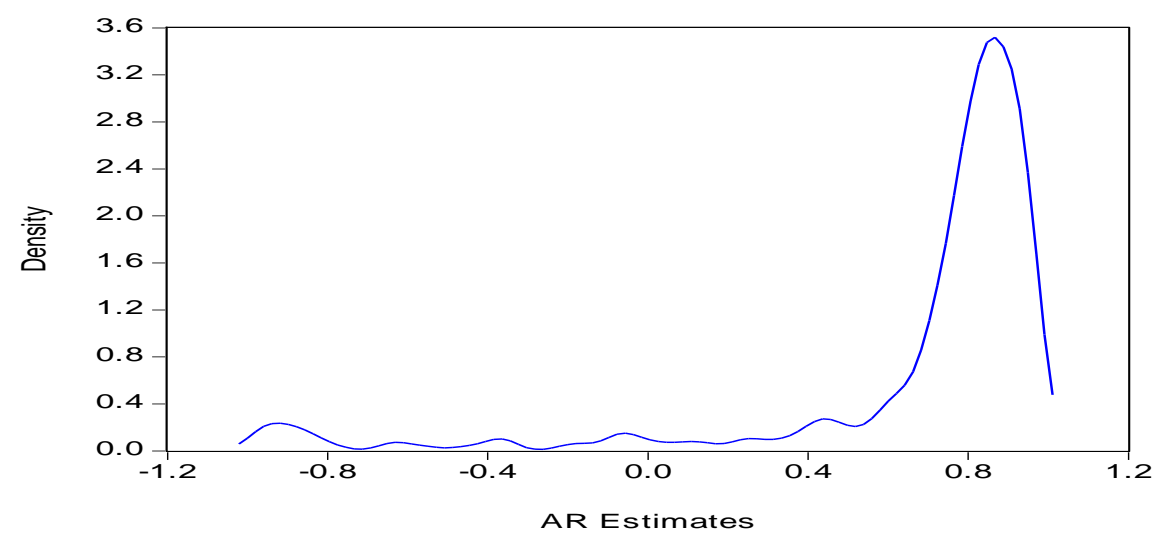

\begin{tabular}{|c|rrrrr|}
\hline Statistics of AR & Mean & Median & Std. Dev. & \multicolumn{1}{c|}{ Skewness } & Kurtosis \\
\cline { 2 - 6 } Estimates & 0.675 & 0.830 & 0.435 & -2.609 & 9.077 \\
\hline
\end{tabular}

Figure 3C Kernel Densitv of MA Estimates of ARMA(1.1) Process

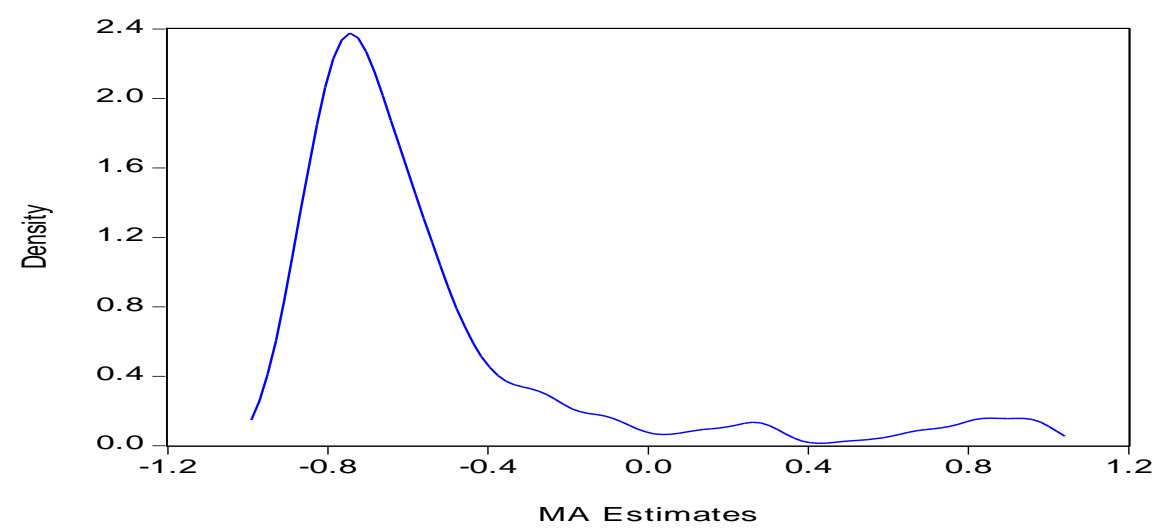

\begin{tabular}{|c|ccrrr|}
\hline Statistics of AR & Mean & Median & Std. Dev. & Skewness & Kurtosis \\
\cline { 2 - 6 } Estimates & -0.538 & -0.670 & 0.414 & 2.261 & 7.710 \\
\hline
\end{tabular}


Figure 4A Kernel Density of AR Estimates of AR(1) Process

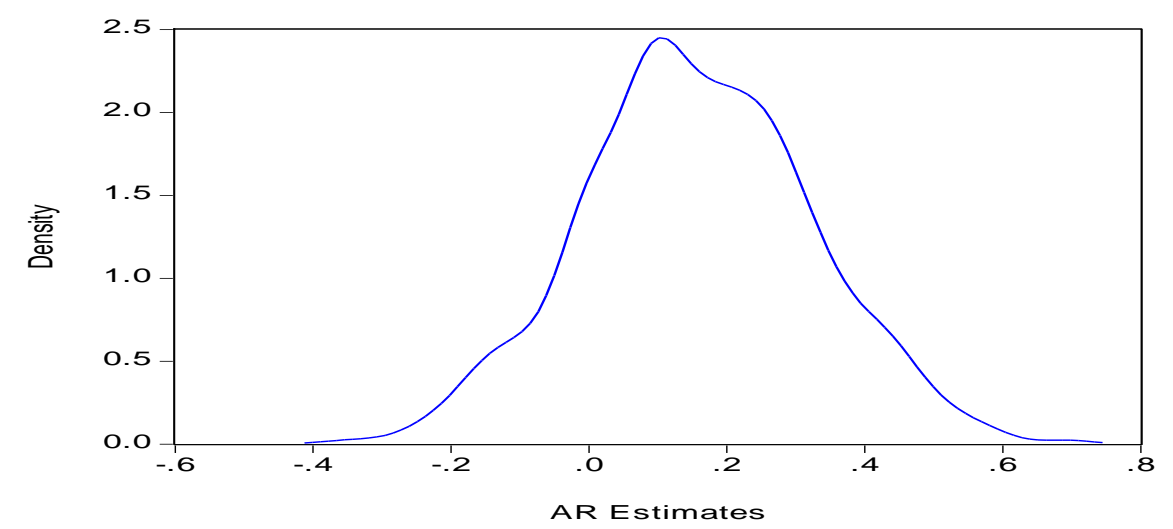

\begin{tabular}{|c|ccccc|}
\hline & Mean & Median & Std. Dev. & Skewness & Kurtosis \\
\hline True AR Parameters & 0.181 & 0.173 & 0.112 & 0.328 & 2.981 \\
\hline Statistics of AR Estimates & 0.156 & 0.150 & 0.166 & 0.051 & 2.961 \\
\hline
\end{tabular}

\section{Figure 4B Kernel Density of AR Estimates of ARMA(1,1) Process}

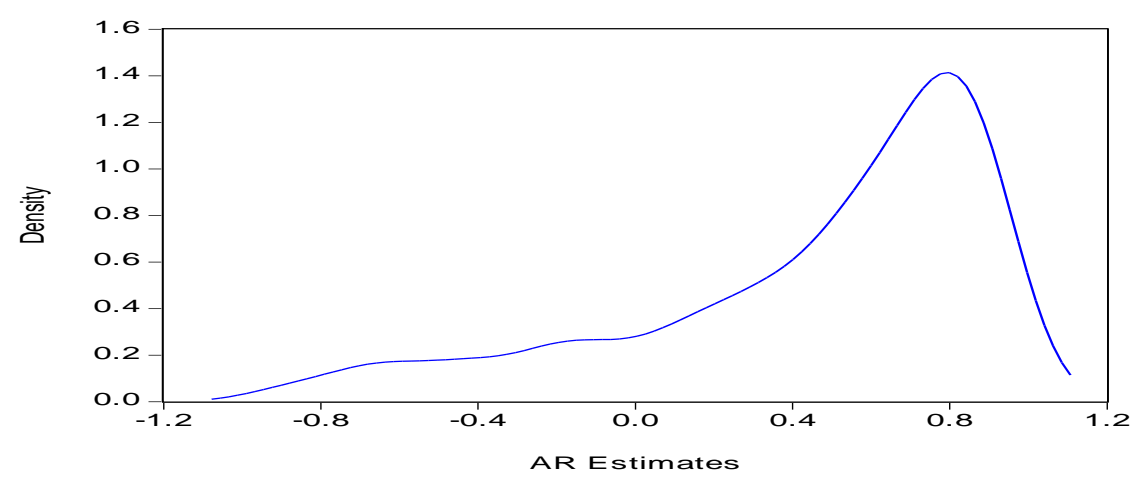

\begin{tabular}{|c|ccccc|}
\hline & Mean & Median & Std. Dev. & Skewness & Kurtosis \\
\hline True AR Parameters & 0.797 & 0.840 & 0.163 & -2.166 & 8.551 \\
\hline Statistics of AR Estimates & 0.449 & 0.609 & 0.463 & -1.156 & 3.447 \\
\hline
\end{tabular}

Figure 4C Kernel Density of MA Estimates of ARMA(1,1) Process

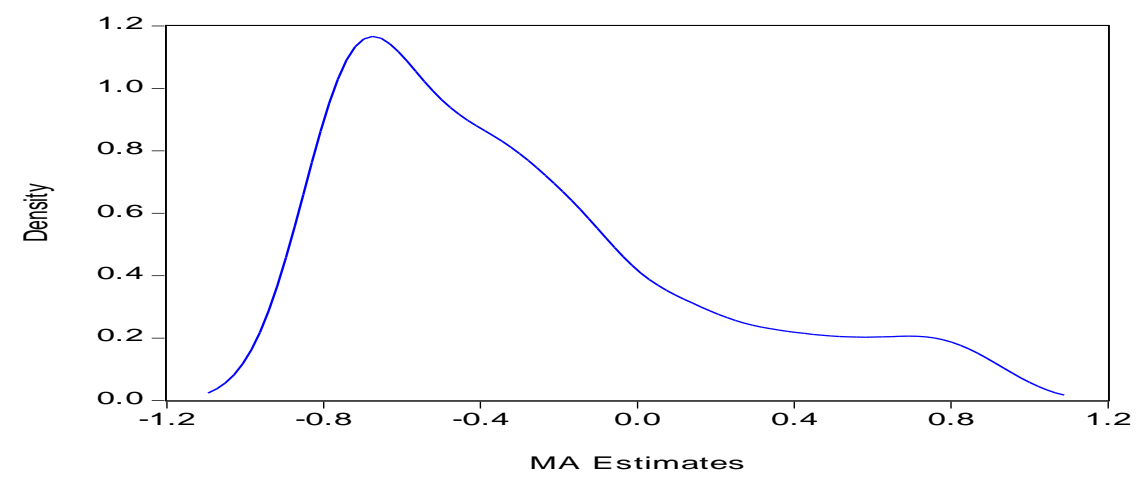

\begin{tabular}{|c|ccccc|}
\hline & Mean & Median & Std. Dev. & Skewness & Kurtosis \\
\hline True MA Parameters & -0.647 & -0.700 & 0.200 & 1.572 & 6.370 \\
\hline Statistics of AR Estimates & -0.301 & -0.413 & 0.458 & 0.963 & 3.094 \\
\hline
\end{tabular}

